\title{
Geri Dönüşümlü Agrega İçeren Betonarme Yüksek Kirişlerin Tasarımı
}

\author{
'İlyas SARIBAŞ \\ ${ }^{1}$ Alparslan Türkeş Bilim ve Teknoloji Üniversitesi, İnşaat Mühendisliği Bölümü, Sarıçam, Adana, Türkiye, \\ E-mail: isaribas@atu.edu.tr
}

\section{Özet:}

Tuğla kırığı ve tuğla tozunun bağlayıcı üretiminde kullanılmasıyla başlayan inşaat ve yıkıntı atıklarının geri dönüşümü, artan makine/ekipman, bilgi ve tecrübeyle hız kazanmıştır. İnşaat ve yıkıntı atıklarının büyük bir kısmını atık betonlar oluşturmaktadır. Atık betonların çevreci yöntemlerle dönüştürmesiyle elde edilen agregaların doğal agregalara alternatif bir ürün olduğunu ortaya koymak için kapsamlı çalışmalar yapılmış ve yapılmaya devam etmektedir. Bu çalışmada, dört farklı oranda geri dönüşümlü agrega içerdiği kabul edilen yüksek kirişlerin tasarımı, mevcut yönetmeliklerin önerdiği bağıntılar kullanılarak çubuk analojisi metoduna göre yapılmıştır. Elde edilen sonuçlar doğal agregalı yüksek kirişlerin tasarım sonuçları ile karşılaştııılmışıı. Elde edilen sonuçlara göre; \%25 oranında geri dönüşümlü agrega içeren yüksek kirişlerin tasarım sonuçların doğal agregalı kirişlerin tasarım sonuçlarına benzediği görülmüştür. Yüksek kirişlerdeki geri dönüşümlü agrega oranı arttıkça bu kirişlerin tasarım sonuçlarının doğal agregalı kirişlerin tasarım sonuçlarından hızla uzaklaştı̆̆ belirlenmiştir. Ayrıca, mevcut yönetmelik bağıntılarının \%25 oranında geri dönüşümlü agrega içeren yüksek kirişlerde geçerli olduğu, bu oranın aşıldığı kirişlerde mevcut bağıntıların kullanılmasının yapısal tasarım açısından risk oluşturacağı tespit edilmiştir.

Anahtar kelimeler: Basınç çubuğu, Çubuk analojisi metodu, Doğal agrega, Geri dönüşümlü agrega, Yüksek kiriş

\section{Design of Reinforced Green Concrete Deep Beams}

\begin{abstract}
:
The recycling process of construction and demolition wastes gained momentum with increasing machinery, knowledge, and experience. The construction and demolition wastes contain a large amount of waste concrete. Many experimental and analytical studies have exhibited that recycled aggregate concrete (green concrete) is alternative to conventional concrete (natural concrete). In this study, the structural design of reinforced green concrete deep beams with four different recycled concrete aggregate ratios $(25 \%, 50 \%, 75 \%$, and $100 \%)$ was executed with the strut and tie method using the suggested procedures by modern structural design codes. The analysis results of reinforced green concrete deep beams were compared with the reinforced conventional concrete deep beam results. Based on this study, the analysis result revealed that the structural behavior of the deep beam containing $25 \%$ recycled concrete aggregate agreed well with the conventional concrete deep beam. However, the reinforced green concrete deep beams behaved differently from the conventional concrete deep beam as the recycled concrete aggregate increased. In addition, while the present code equations are valid for the deep beam with a $25 \%$ recycled concrete aggregate ratio, it was observed that using existing equations in deep beams with $50 \%, 75 \%$, and $100 \%$ recycled concrete aggregate ratios is inconvenient.
\end{abstract}

Keywords: Strut, Strut and tie method, Natural aggregate, Recycled concrete aggregate, Deep beam. 


\section{Giriş}

Ekonomik faaliyetler ve hane halkı tarafından üretilen atık istatistikleri incelendiğinde inşaat ve yıkıntı atıkları ile maden ve taş ocağı atıklarının toplam atıklar içerisindeki oranının yaklaşık olarak \%63 olduğu belirtilmiştir (Şekil 1) [1]. Ortaya çıkan bu atığın yaklaşık olarak \%70'lik kısmını atık betonlar ve agrega üretiminde kullanılacak malzemeler oluşturmaktadır. $\mathrm{Bu}$ oranlar dikkate alındığında, atık betonların çevreci veya ekonomi etkin yöntemlerle bertaraf edilmesi gerekmektedir. Atık betonların ortadan kaldırılması için son yıllarda bir den fazla yöntem geliştirilmekle beraber bu yöntemlerden en etkili olanı 4R: Atıkları azaltmak, yeniden kullanmak, geri dönüştürmek ve yeniden satmak veya satın almak (Reduce, Reuse, Recycle, Rebuy veya Resell) yöntemidir [2]. Bu yöntemle atık betonlar, kaynağında yeniden kullanılmak suretiyle azaltılmakta veya geri dönüştürülerek ekonomiye kazandırılmaktadır. Bu yöntemi uygulayan gelişmiş ve gelişmekte olan ülkelerin inşaat sektörü kaynaklı doğaya salınan karbon monoksit miktarında önemli azalmaların olduğu belirtilmiştir [1-2].

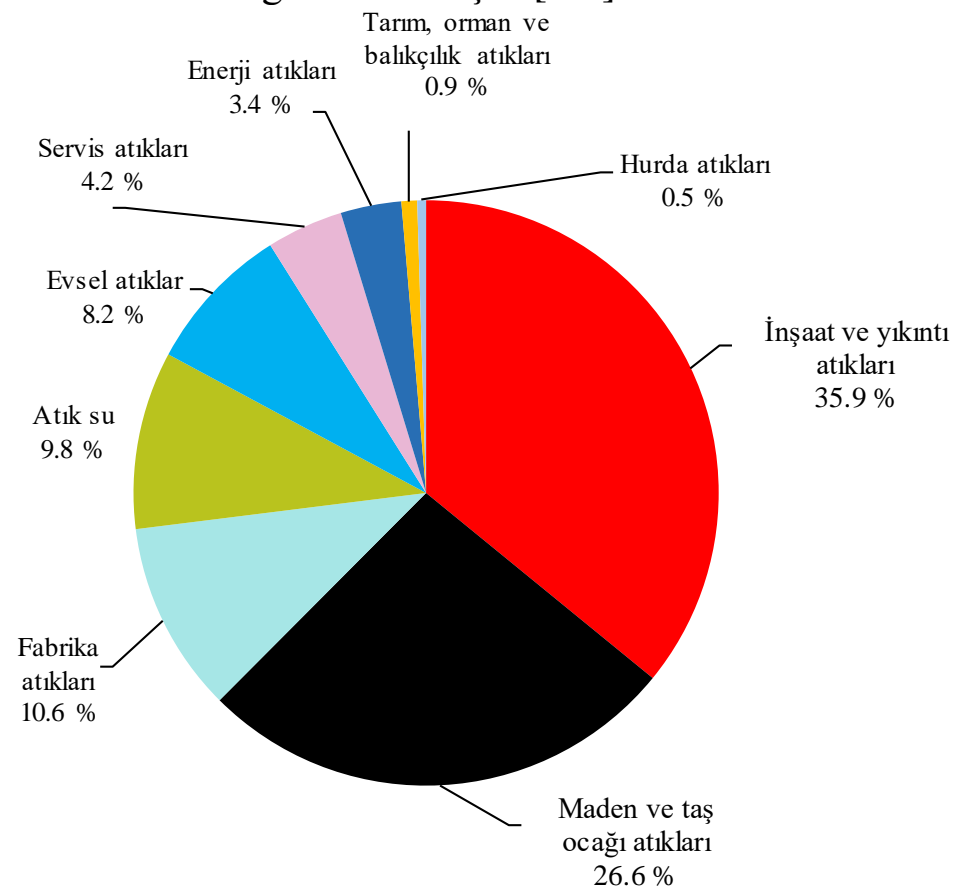

Şekil 1. Ekonomik faaliyetler ve hane halkı aktiviteleri soncunda ortaya çıkan atıklar (toplam atık içerisinde \% olarak) [1]

Atık betonların geri dönüştürülmesiyle elde edilen malzeme geri dönüşümlü agrega (GDA), geri dönüştürülmüş agrega veya geri kazanılmış agrega olarak isimlendirilmektedir. Bu agreganın doğal agregaya (DA) alternatif bir ürün olup olmadığını ortaya koymak için yıllardır kapsamlı çalışmalar yapılmış ve yapılmaya devam etmektedir. Yapılan çalışmaların çoğunda bu agreganın belirli koşullar altında DA'ya alternatif bir ürün olabileceği belirtilmiştir [3-17]. Ayrıca, yapısal olmayan veya ekstrem yükleme koşullarına maruz kalmayacak elemanların üretiminde kullanılacak GDA için malzeme kriterleri olabildiğince esnektir. Beton ve türevi malzemelerden üretilen yapıları dikkate aldığımızda, bu yapıların hem normal hem de ekstrem yükleme koşullarında (doğal afetler özellikle depremler) servis ömrüne devam etmesi gerekmektedir. Dolayısıyla statik ve dinamik etkilere maruz kalabilecek yapıların üretiminde GDA kullanımına dikkat etmek gerekmektedir. 
Literatürde farklı oranda geri dönüşümlü agrega içeren betondan (GDAB) üretilen yapılar ve yapısal elemanların statik ve dinamik yükler altındaki performansları araştırılmıştır. Yapılan araştırmalar da bu elemanların statik ve dinamik yükleme koşullarındaki performanslarına etki eden kritik GDA eşik oranının \%25-\%35 arasında olduğu ifade edilmiştir [3-11]. \%25 ve altında GDA kullanımının (kullanılan agreganın karakteristik özelliğine bağlı olarak bu oran \%35'e bazen de \%50'ye kadar çıkabiliyor) yapısal elemanların ve yapıların performanslarına etkisinin ihmal edilebilir düzeyde olduğu belirtilmiştir. Ayrıca, bu durum büyük boyutlu ve yapısal/sismik etkilere maruz kalan elemanlar için geçerlidir. Küçük boyutlu silindir vb. elemanlar, GDA oranından daha fazla etkilenebilmektedirler. Büyük boyutlu numunelerde GDA oranı için kritik eşik \%25-\%35 iken, küçük boyutlu numunelerde bu oran daha aşağıya (örneğin \%25 ve altı) düşebilmektedir [317]. Dolayısıyla büyük boyutlardaki elemanların GDA'nın negatif yönlerini daha fazla tolere ettiği çıkarılabilecektir.

Betonarme elemanların tamamına yakını B ve/veya D bölgelerinden oluşurlar. B bölgeleri Bernoulli-Navier hipotezine uyan bölgeler diğer bölgeler ise D bölgeleri (Disturbed-Discontinuity Regions) olarak isimlendirilirler (Şekil 2). Bernoulli-Navier hipotezinin geçerli olduğu ve GDAB ile üretilen yapısal elemanların statik ve dinamik etkiler altındaki performanslarının araştırılmasına yönelik deneysel ve teorik bazı çalışmalar yapılmıştır. Ancak, GDAB'dan her türlü betonarme elemanın üretilebileceği düşünüldüğünde, bu hipotezin geçerli olmadığı D bölgeli yapısal elemanların davranışı da araştırılması gereken konulardandır. D bölgeleri, B bölgelerinden farklı olarak hem geometrik hem de statik olarak süreksiz bölgeler olduğu için bu bölgelerin tasarımı için bazı metotlar geliştirilmiştir.

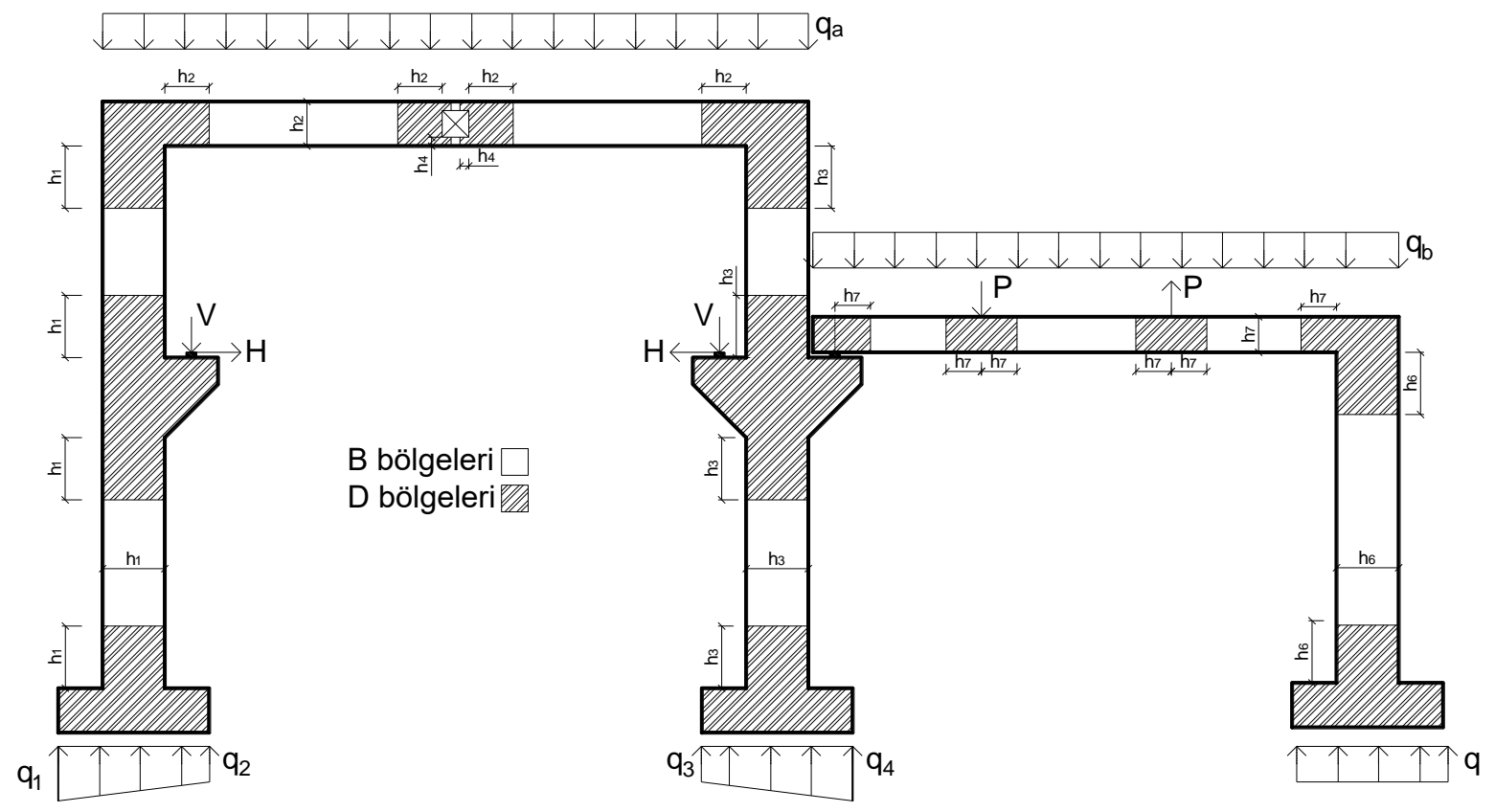

Şekil 2. Betonarme çerçevede B ve D bölgeleri [31]

Bu metotlardan birisi de Ritter [18] ve Mörsch [19-20] tarafından önerilen çubuk analojisi metodudur (strut and tie method). Bu yöntem daha sonra bazı araştırmacılar tarafından modifiye edilerek, D bölgelerinin tasarımı için birden fazla uluslararası yönetmelik [21-28] tarafından 
tavsiye edilen metot haline gelmiştir. Bu çalışma kapsamında, dört farklı oranda geri dönüşümlü agrega içerdiği kabul edilen yüksek kirişlerin tasarımı, mevcut yönetmeliklerin önerdiği bağıntılar kullanılarak çubuk analojisi metoduna göre yapılmıştır. Elde edilen sonuçlar doğal agregalı yüksek kirişlerin tasarım sonuçları ile karşılaştırılmıştır. Ayrıca, D bölgelerinin tasarımı için uluslararası yönetmelikler tarafından önerilen beton parametrelerinin GDAB için geçerli olup olmadığı kapsamlı olarak incelenmiştir.

\section{Materyal ve Metot}

Geri dönüşümlü agrega içeren betonun gerilme-şekildeğiştirme ilişkisini elde etmek için bazı araştırmacılar tarafından beton modelleri önerilmiştir [11-17]. Bu çalışma kapsamında Saribas [17] tarafından önerilen modifiye Hognestad [29] modeli kullanılmıştır. Bu model kullanılarak basit yöntemlerle GDAB için gerilme-şekildeğiştirme ilişkileri elde edilebilmektedir. Bu çalışmada yüksek kirişlerin beton özelliğini temsil edecek 5 farklı beton türü dikkate alınmıştır. Bu beton türleri, tamamen DA'dan üretilen beton (DAB), sırasıyla ağırlıkça \% 25 oranında GDA içeren beton (GDAB25), \%50 GDA içeren beton (GDAB50), \%75 GDA içeren beton (GDAB75) ve tamamen GDA'dan üretilen betondur (GDAB100). Bu betonların gerilme-şekil değiştirme ilişkileri Şekil 3a'da verilmiştir. Betonarme çeliği için ise detayları Türkiye Bina Deprem Yönetmeliği 2018'de (TBDY 2018) [30] verilen B420C donatı çeliği kullanılmıştır. Bu donatıya ait gerilmeşekildeğiştirme ilişkisi Şekil 3b’de verilmiştir.

(a)

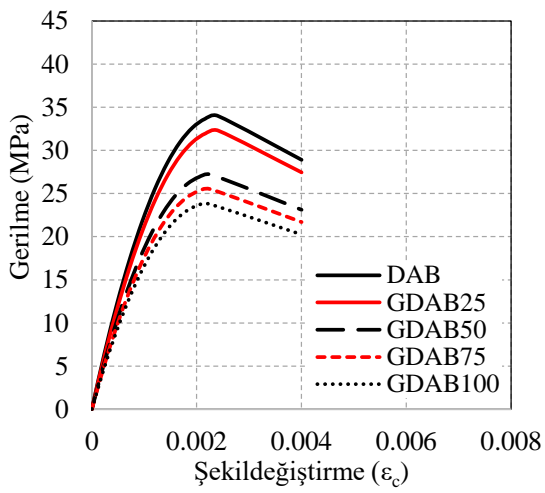

(b)

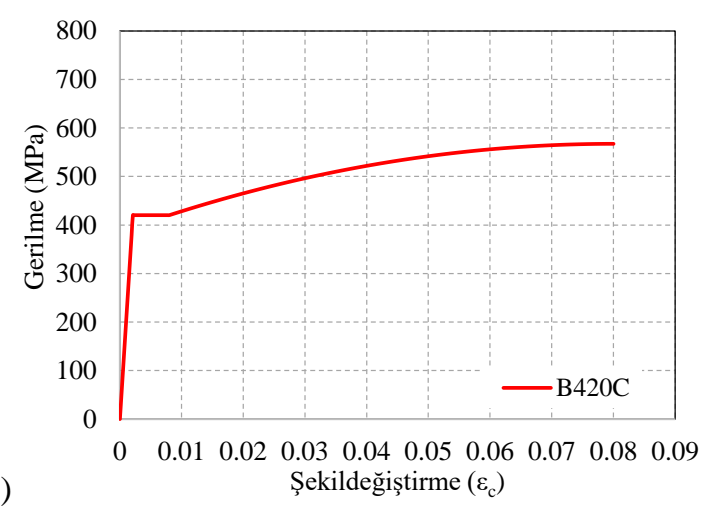

Şekil 3. Gerilme-ş̧ekildeğiştirme ilişkileri; (a) farklı oranda GDA içeren betonlar, (b) B420C donatı çeliği [17, 30]

\section{D bölgelerinde Basınç Çubukları ve Düğüm Noktaları}

Çubuk analojisi metodu betonarme ve prefabrik yapısal elemanların statik ve geometrik olarak süreksiz olan $\mathrm{D}$ bölgelerinin tasarımında kullanılan yöntemdir. $\mathrm{Bu}$ yöntemde $\mathrm{D}$ bölgelerinin tasarımı için üç ana eleman dikkate alınmaktadır. Bunlar: basınç çubuğu, çekme çubuğu ve bu iki çubuğunun birleşim noktasını ifade eden düğüm noktasıdır. D bölgeli yapısal elemanlarda basınç çubukları basınç gerilmelerine, çekme çubukları çekme gerilmelerine maruz kalmaktadır. Ayrıca, yükleme koşulları ve malzeme parametreleri dikkate alındığında, basınç çubukları 3 farklı şekilde karşımıza çıkabilmektedir. Bunlar: prizmatik, şişe ve yelpaze tipi basınç çubuklarıdır. Çekme çubukları donatı çeliği ile temsil edildiği için bu elemanlar klasik donatı şekliyle gösterilmektedir (Şekil 4). 

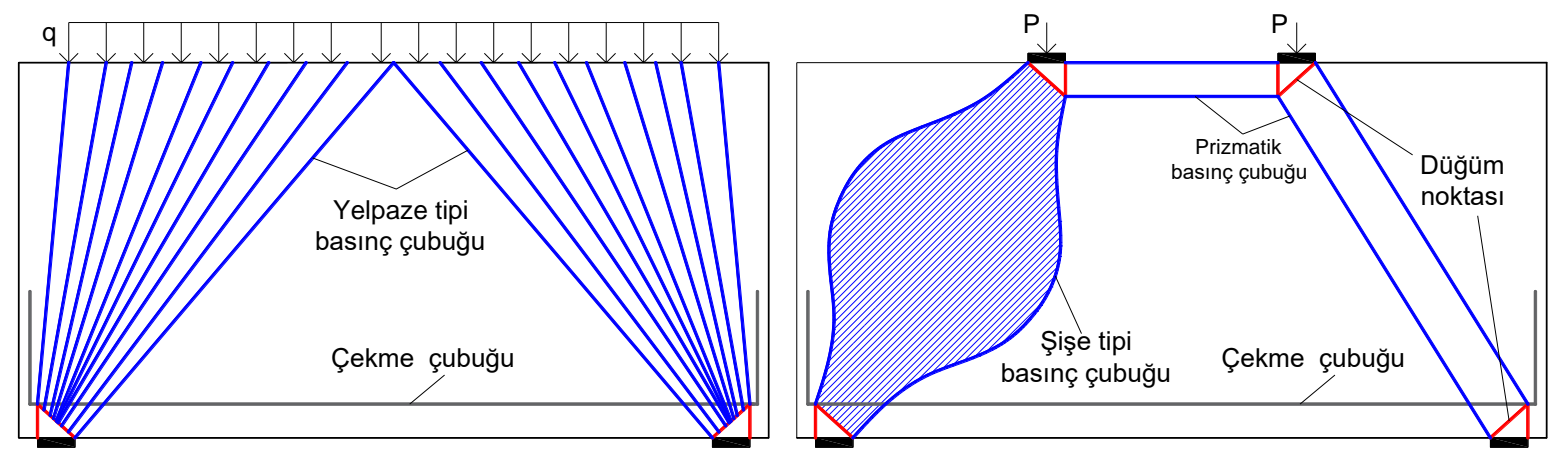

Şekil 4. Çubuk analojisi metodunda basınç ve çekme çubukları

Basınç ve çekme çubuklarının birleşim şekline göre düğüm noktaları farklı isimler alabilmektedir. Bunlar: basınç-basınç-basınç birleşimi (C-C-C) dügüum noktası, basınç-basınç-çekme birleşimi (CC-T) düğüm noktası ve basınç-çekme-çekme birleşimi (C-T-T) düğüm noktasıdır (Şekil 5). Ayrıca, düğüm noktalarındaki gerilme durumları hidrostatik veya hidrostatik olmayan şeklinde ikiye ayrilmaktadır.
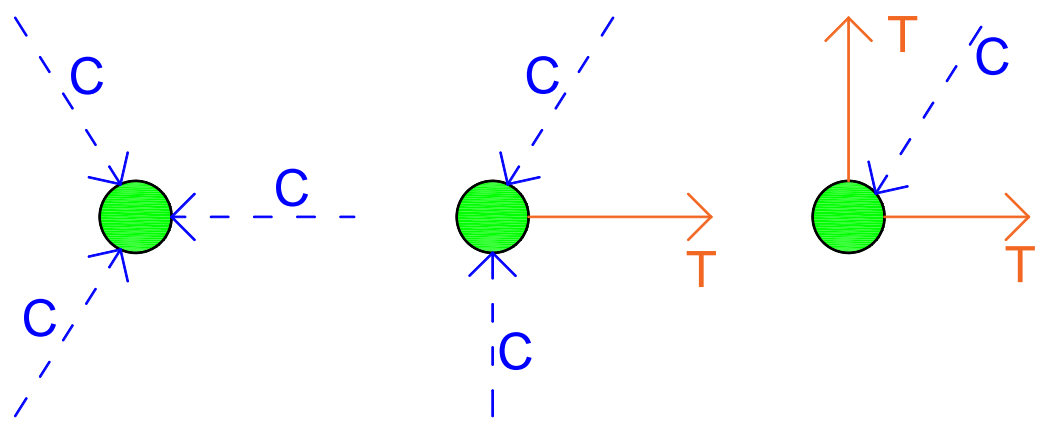

Şekil 5. Çubuk analojisi metodunda düğüm noktaları [21]

Çubuk analojisi metodunda beton parametreleri, basınç çubukları ve düğüm noktalarının karakteristik özelliklerine etki etmektedir. D bölgelerinin tasarımında basınç çubukları ve düğüm noktaları için uluslararası yönetmelikler tarafından önerilen bağıntılar Tablo 1'de verilmiştir. Verilen ilişkiler detaylı olarak incelendiğinde basınç çubuğu kapasitesinin, beton türü, çatlak tipi, çatlak açısı, basınç çubuğu türü, çatlamış veya çatlamamış kesit gibi parametrelere bağlı olduğu görülmektedir. Düğüm noktalarındaki basınç gerilmesiyse düğüm noktası tipine bağlı olarak farklılık göstermektedir. Hem basınç çubuğu kapasitesinin hem de düğüm noktası basınç gerilmesinin beton karakteristik özelliklerinden önemli oranda etkilenmesi, GDAB ile üretilecek D bölgeli yapısal elemanların tasarımını önemli kılmaktadır. Çünkü GDAB' da karışıma giren GDA oranının artmasıyla betonun basınç dayanımı ve elastisite modülü değerinin belirli oranda azaldığı görülmüştür (Şekil 3) [11-17]. Dolayısıyla GDAB ile üretilecek D bölgeli yapısal elemanın tasarımında yönetmelikler tarafından DAB için önerilen ifadelerin kullanılması D bölgelerinin gerçekçi olarak tasarlanmasını engelleyebilecektir. Bu çalışmada, betonarme yüksek kirişlerinin çubuk analojisi metoduna göre tasarımında beş farklı beton türü (DAB, GDAB25, GDAB50, GDAB75 ve GDAB100) dikkate alınmıştır. D bölgelerinin tasarımında farklı beton türlerinin tasarım kriterlerini ne yönde etkilediği kapsamlı olarak incelenmiştir. Elde edilen sonuçlar takip eden bölümlerde detaylı olarak verilmiştir. 
Tablo 1. Basınç çubukları ve düğ̈̈m noktaları için mevcut yönetmelik kriterleri [31]

\begin{tabular}{|c|c|c|}
\hline Yönetmelik & Basınç çubuğu kapasitesi (donatısız) & $\begin{array}{l}\text { Düğüm noktası basınç } \\
\text { gerilmesi }\end{array}$ \\
\hline ACI 318-19 [21] & $\begin{array}{l}0.85 \beta_{s} f_{c}^{\prime} A_{c s} \\
\text { Prizmatik: } \beta_{s}=1.0 \\
\text { Sişe tipi donatill: } \beta_{s}=0.75 \\
\text { Şişe tipi donatısı: } \beta_{s}=0.60 \lambda \\
\lambda=1.0 \text { normal dayanımlı beton } \\
\lambda=0.85 \text { hafif beton (kum içeren normal dayanıml1) } \\
\lambda=0.75 \text { tüm hafif beton tipleri } \\
\text { Çekme elemanlarındaki basınç durumu: } \beta_{s}=0.4 \\
\text { Diğer tüm durumlar: } \beta_{s}=0.6\end{array}$ & $\begin{array}{l}0.85 \beta_{n} f^{\prime} c \\
\text { CCC: } \beta_{n}=1.0 \\
\text { CCT: } \beta_{n}=0.8 \\
\text { CTT: } \beta_{n}=0.6\end{array}$ \\
\hline CSA A23.3 [22] & $\begin{array}{l}f_{c u} A_{c s} \\
f_{c u}=\frac{f_{c}^{\prime}}{0.8+170 \varepsilon_{1}} \leq 0.85 f_{c}^{\prime} \\
\varepsilon_{1}=\varepsilon_{s}+\left(\varepsilon_{s}+0.02\right) \cot ^{2} \alpha_{s}\end{array}$ & $\begin{array}{l}\text { CCC: } 0.85 f^{\prime}{ }^{c} \\
\text { CCT: } 0.75 f^{\prime} c \\
\text { CTT: } 0.65 f^{\prime}{ }^{\prime} c\end{array}$ \\
\hline CSA S6-6 [23] & $\begin{array}{l}f_{c u} A_{c s} \\
f_{c u}=\frac{f_{c}^{\prime}}{0.8+170 \varepsilon_{1}} \leq \alpha_{1} f_{c}^{\prime} \\
\varepsilon_{1}=\varepsilon_{s}+\left(\varepsilon_{s}+0.02\right) \cot ^{2} \theta_{s} \\
\alpha_{1}=0.85-0015 f_{c}^{\prime}\end{array}$ & $\begin{array}{l}\text { CCC: } \alpha_{l} \psi_{c} f_{c}^{\prime} \\
\text { ССТ: } 0.88 \alpha_{l} \psi_{c} f_{c}^{\prime} \\
\text { СТT: } \alpha_{l} f_{c}^{\prime} c\end{array}$ \\
\hline DIN 1045-1 [24] & $\begin{array}{l}1.0 \eta_{1} f_{c d} A_{c s}: \text { Çatlamamış beton basınç bölgesi } \\
0.75 \eta_{1} f_{c d} A_{c s}: \text { Çatlağa paralel } \\
\eta_{1}=1.0 \text { normal dayanımlı beton, } \\
\eta_{1}=0.4+0.6(\rho / 2200) \text { hafif dayanımlı beton, }\end{array}$ & $\begin{array}{l}\text { CCC: } 1.1 \eta_{1} f_{c d} \\
\text { CCT, CTT: } 0.75 \eta_{1} f_{c d} \quad \theta s \geq 45 \\
\eta_{1}=1.0 \text { normal beton } \\
\eta_{1}=0.4+0.6(\rho / 2200) \text { hafif beton }\end{array}$ \\
\hline NZS 3101[25] & $\begin{array}{l}0.85 \beta_{s} f_{c}^{\prime} A_{c s} \\
\text { Prizmatik: } \beta_{s}=1.0 \\
\text { Sişe tipi donatıll: } \beta_{s}=0.75 \\
\text { Şişe tipi donatısı: } \beta_{s}=0.60 \lambda \\
\lambda=1.0 \text { normal dayanımlı beton } \\
\lambda=0.85 \text { hafif beton (normal dayanımlı kum içeren) } \\
\lambda=0.75 \text { tüm hafif beton tipleri } \\
\text { Çekme elemanlarındaki basınç durumu: } \beta_{s}=0.4 \\
\text { Diğer tüm durumlar: } \beta_{s}=0.6\end{array}$ & $\begin{array}{l}0.85 \beta_{n} f^{\prime} c \\
\text { CCC: } \beta_{n}=1.0 \\
\text { CCT: } \beta_{n}=0.8 \\
\text { CTT: } \beta_{n}=0.6\end{array}$ \\
\hline AASHTO LRFD [26] & $\begin{array}{l}f_{c u} A_{c s} \\
f_{c u}=\frac{f_{c}^{\prime}}{0.8+170 \varepsilon_{1}} \leq 0.85 f_{c}^{\prime} \\
\varepsilon_{1}=\varepsilon_{s}+\left(\varepsilon_{s}+0.02\right) \cot ^{2} \alpha_{s}\end{array}$ & $\begin{array}{l}\text { CCC: } 0.85 f^{\prime}{ }^{\prime} c \\
\text { CCT: } 0.75 f^{\prime \prime} c \\
\text { CTT: } 0.65 f^{\prime}{ }^{\prime} c\end{array}$ \\
\hline $\begin{array}{l}\text { CEB-FIP } \\
\text { Model Code } 90 \text { [27] }\end{array}$ & $\begin{array}{l}f_{c d 1} A_{c s} \text { veya } f_{c d 2} A_{c s} \\
\text { Çatlamamış beton basınç bölgesi: } f_{c d 1}=0.85\left(1-\frac{f_{c k}}{250}\right) f_{c d} \\
\text { Çatlamıs beton basınç bölgesi: } f_{c d 2}=0.60\left(1-\frac{f_{c k}}{250}\right) f_{c d}\end{array}$ & $\begin{array}{l}\text { ССС, ССТ, СТT: } \\
0.85\left(1-\frac{\mathrm{f}_{\mathrm{ck}}}{250}\right) \mathrm{f}_{\mathrm{cd}}, \theta \mathrm{s} \geq 55 \\
\text { ССТ, СТT: } 0.60\left(1-\frac{f_{c k}}{250}\right) f_{c d}\end{array}$ \\
\hline $\begin{array}{l}\text { FIP Recommendations } \\
\text { [28] }\end{array}$ & $\begin{array}{l}f_{c d, e f f} A_{c}=v_{1} f_{1 c d} A_{c s} \text { veya } v_{2} f_{1 c d} A_{c s} \\
v_{1}=\left(1-\frac{f_{c k}}{250}\right): \text { dikdörtgen çatlamamış basınç bölgesi } \\
v_{2}=1.0 \text { uniform çatlamamış şekildeğiştirme durumu } \\
v_{2}=0.8 \text { çatlağa paralel } \\
v_{2}=0.6 \text { basıç bölgesinde kü̈cük çatlaklar } \\
v_{2}=0.8 \text { basıç bölgesinde büyük çatlaklar }\end{array}$ & $\begin{array}{l}\text { CCT ve CTT: } v_{2} f_{I c d,} v_{2}=0.85 \\
\text { CCC: İki eksenli basınç: } 1.20 f_{\text {Icd }} \\
\text { Üç eksenli basınç: } 3.88 f_{I c d}\end{array}$ \\
\hline
\end{tabular}




\section{Yüksek Kirişlerin Çubuk Analojisi Metoduna Göre Tasarımı}

Yüksek kirişlerin boyutları, mesnetlenme koşulları ve yükleme durumu seçilecek çubuk modeline etki etmektedir. Bu çalışmada, D bölgeleri tasarımı için mevcut yönetmelikler tarafından önerilen geleneksel yöntemlerin GDAB içeren elemanlarda kullanılabilirliği araştırılmaktadır. Bundan dolayı çalışmanın amacına hizmet edecek temel seviyede bir yüksek kiriş seçilmiştir. Seçilen yüksek kirişin boyutları, mesnetlenme ve yükleme koşulları Şekil 6'da verilmiştir. Bu kirişte mesnetler arası açıklığın (L) kiriş yüksekliğine (h) oranı $1.33<1.50$ olduğu için Şekil 6'daki gibi bir çubuk modeli seçilmiştir. Seçilen modelde GDA'nın tasarım parametrelerine etkisini tam olarak görebilmek için tüm yüksek kirişlerde basınç çubuğu genişliği (BÇG) $65 \mathrm{~mm}$, mesnet basınç çubuğu genişliği (MBÇG) $50 \mathrm{~mm}$ ve yük altı basıç çubuğu genişliği (YBÇG) $90 \mathrm{~mm}$ olarak dikkate alınmıştır (Tablo 2; durum 1). Yüksek kirişlerin tamamında çekme çubuğu genişliği optimum genişlik olan 30 mm'dir. Seçilen çubuk modelde, yük altı düğüm noktasında C-C-C, sabit ve kayıcı mesnet noktalarında C-C-T tipi düğüm noktaları seçilmiştir (Şekil 6).

Yüksek kirişlerin tasarımında CAST yazılımı kullanılmıştır. Ayrıca, çubuk analojisi metoduna göre tasarımda literatürde çokça kabul gören ve yazılımda hazır olarak verilen ACI 318-19 [21] yönetmeliği kullanılmıştır. Seçilen çubuk modeli dikkate alınarak yapılan tasarım sonuçları Şekil 7 ve 8'de verilmiştir. Bu sonuçlara göre yüksek kirişlerdeki basınç çubuğu elemanlarının kapasite ve kesit artış talebinin yüksek kirişlerdeki GDA oranı arttıkça yükseldiği ve bu durumun çubuklarda zorlanmalara neden olduğu görülmüştür (Şekil 7). Ayrıca, aynı boyut, mesnetlenme ve yükleme koşullarındaki kirişlerin, çekme çubuklarındaki kapasite artış isteminin tüm beton türleri için aynı olduğu ve mevcut durumun yeterli olduğu belirlenmiştir (Şekil 7).
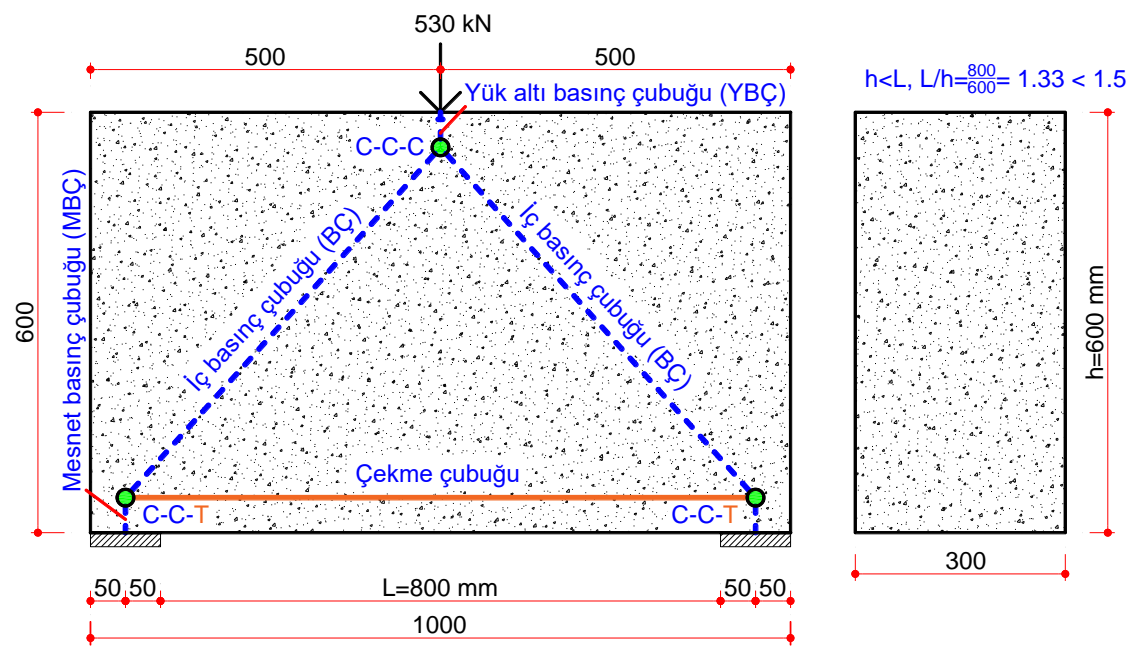

Şekil 6. Yüksek kiriş boyutları, yük, mesnetlenme koşulları ve seçilen çubuk modeli

Yüksek kirişlerdeki basınç çubuğu etkili kapasite seviyesinin $(\mathrm{O} / \mathrm{S})$ yaklaşık olarak 0.90 olduğu, GDA oranı arttıkça basınç çubuklarının aşırı derecede zorlandığı görülmüştür (Şekil 7-8a). Basınç çubuklarındaki GDA oranına bağlı zorlanmaları ortadan kaldırmak ve çubuk kapasitelerini optimum seviyeye (etkili kapasite seviyesi) getirmek için basınç çubuğu kesitlerinin arttırılması gerekmektedir. Basınç çubuklarındaki kesit artış talebi değerlendirildiğinde, bu talebin tüm basınç çubuğu tiplerinde yaklaşık olarak GDAB25 için \%5, diğer beton türleri için ise sırasıyla 
GDAB50'de \%25, GDAB75'te \%35 ve GDAB100'de \%45 olduğu görülmüştür (Şekil 8b). Bu kesit artış talebi her eleman için karşılandığında, basınç çubuğu kesitleri için GDA oranının fazla olduğu (\%50, \%75, \%100) yüksek kirişlerde önemli artışlar meydana gelmiştir (Şekil 8c, Tablo 2; durum 2). Örneğin, yük altı basınç çubuğunda (YBÇ), optimum basınç çubuğu kapasitesini elde edebilmek için GDAB25 için 5 mm, GDAB 50 için 22 mm, GDAB75 için 30 mm ve GDAB100 için 39 mm kesit artışı gerçekleştirilmiştir (Tablo 2; durum 2, Şekil 8c). Aynı artış; iç basınç çubuğu (BÇ), mesnet basınç çubuğu (MBÇ) içinde geçerlidir.

(a)

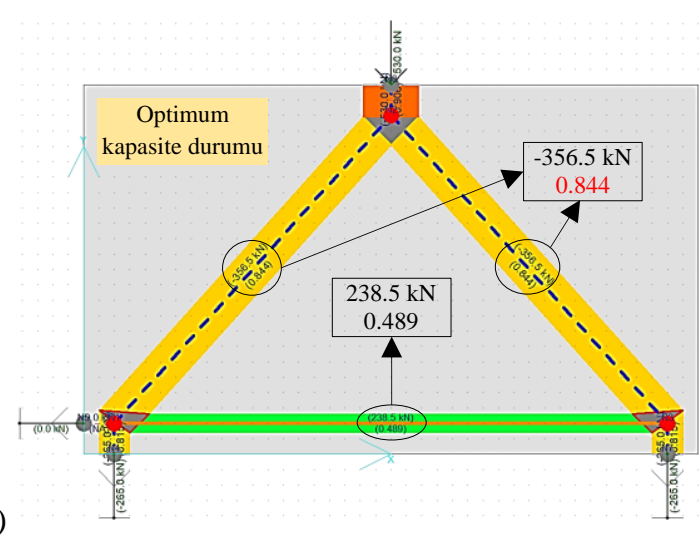

(c)

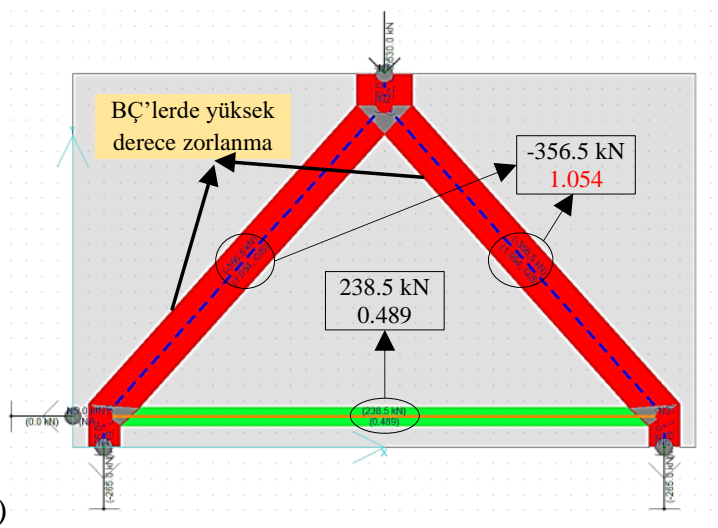

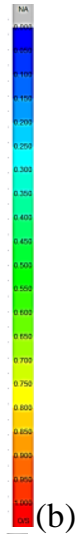
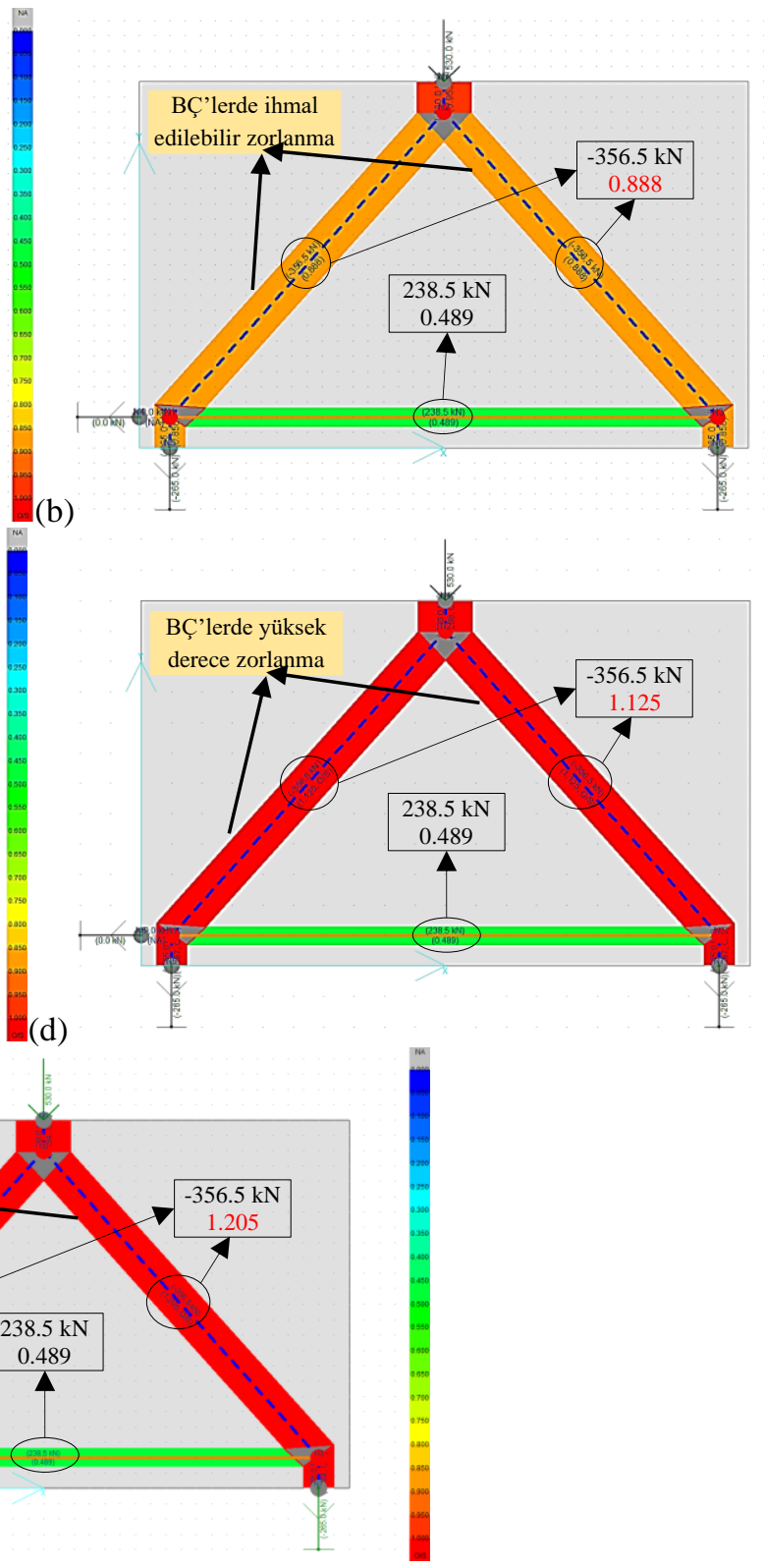

(e)

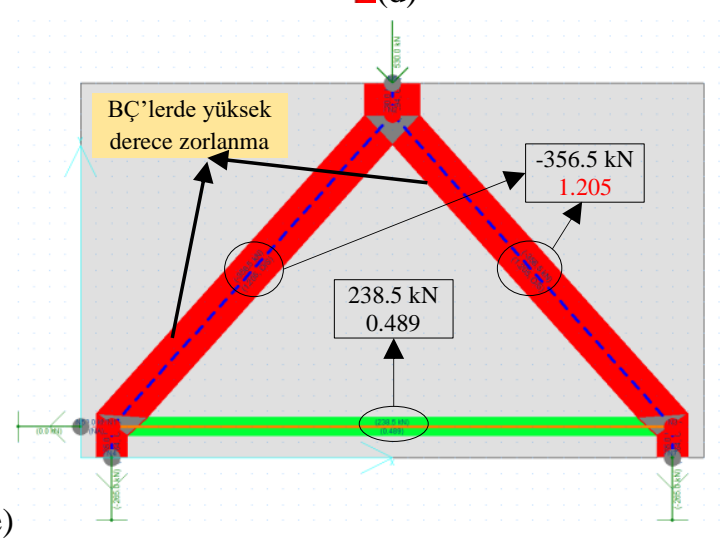

GDAB75_YK, (e) GDAB100-YK 
Tablo 2. Basınç çubuğu genişlikleri (mm)

\begin{tabular}{|c|c|c|c|c|}
\hline & Yüksek kirişler (YK) & $B C ̧ G(\mathrm{~mm})$ & $M B C ̧ G(\mathrm{~mm})$ & $Y B C ̧ G(\mathrm{~mm})$ \\
\hline \multirow{5}{*}{$\underset{\vdots}{\vdots}$} & $D A B-Y K$ & \multirow{5}{*}{65.0} & \multirow{5}{*}{50.0} & \multirow{5}{*}{90.0} \\
\hline & $G D A B 25-Y K$ & & & \\
\hline & GDAB50-YK & & & \\
\hline & $G D A B 75-Y K$ & & & \\
\hline & $G D A B 100-Y K$ & & & \\
\hline \multirow{5}{*}{$\underset{\vdots}{N}$} & $D A B-Y K$ & 65.0 & 50.0 & 90.0 \\
\hline & $G D A B 25-Y K$ & 68.0 & 53.0 & 95.0 \\
\hline & GDAB50-YK & 81.0 & 62.0 & 112.0 \\
\hline & $G D A B 75-Y K$ & 87.0 & 67.0 & 120.0 \\
\hline & $G D A B 100-Y K$ & 93.0 & 72.0 & 129.0 \\
\hline
\end{tabular}

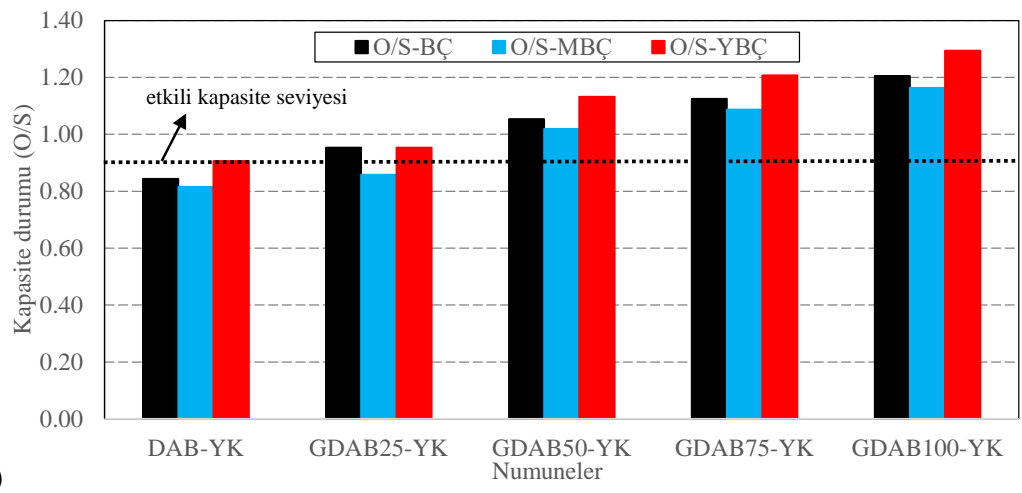

(a)

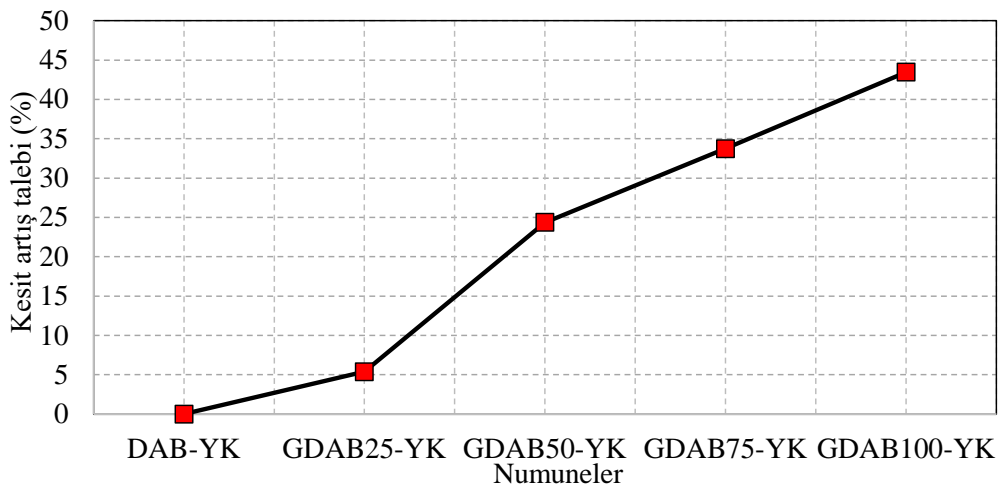

(b)

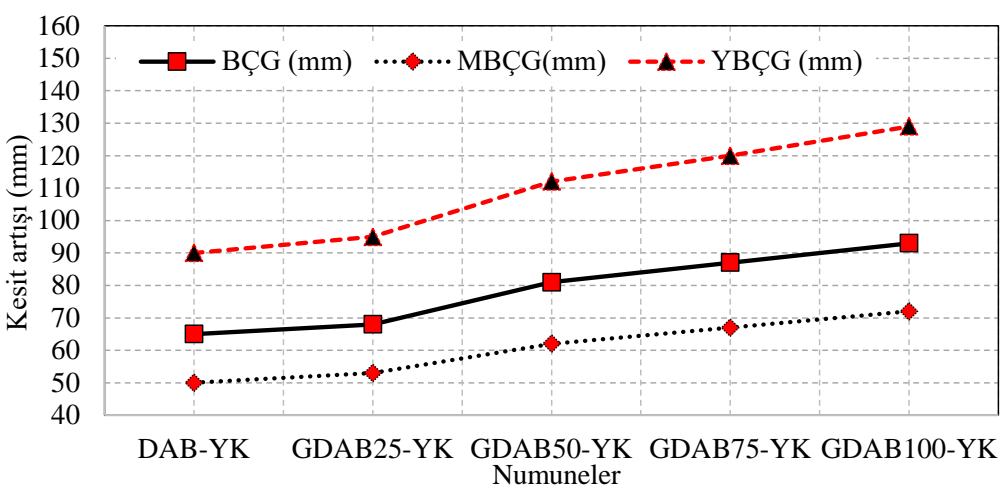

Şekil 8. (a) Basınç çubuğu kapasite durumu (O/S), (b) basınç çubuğu kesit artış talebi (\%), (c) basınç çubuğu kesit $\operatorname{artışı~}(\mathrm{mm})$ 
Farklı betonlardan üretildiği kabul edilen yüksek kirişlerin çubuk analojisi metoduna göre yapılan tasarım sonuçlarından, mevcut yönetmelik koşullarının (ACI 318-19 [21]), GDAB25 için geçerli olduğu görülmüştür. Diğer beton türlerinin (GDAB50, GDAB75 ve GDAB100) yüksek kirişlerin tasarımın da dikkate alınabilmesi, ayrıca kapasite etkin bir tasarım yapılabilmesi için mevcut bağıntıların (ACI 318-19 [21]) GDA oranına bağlı olarak kapasite artış talebini karşılayacak şekilde revize edilmesi gerektiği tespit edilmiştir. Basınç çubuğu ve düğüm noktası kapasitelerinin belirlenmesinde beton basınç dayanımı $\left(f^{\prime}{ }_{c}\right)$ bağıntılara çarpan olarak girmektedir (Tablo 1). Dolayısıyla, ACI 318-19 [21] için elde edilen sonuçlar Tablo 1'de verilen diğer yönetmelikler içinde geçerlidir. Sonuç olarak, \%50 ve üzerinde GDA içeren betondan üretilecek olan D bölgeli yapısal elemanların tasarımında mevcut yönetmelik bağıntıların kullanılması yapısal tasarım açısından sakıncalıdır.

\section{Sonuçlar}

$\mathrm{Bu}$ çalışma kapsamında, dört farklı oranda GDA içeren yüksek kirişlerin tasarımı mevcut yönetmeliklerin önerdiği bağıntılar kullanılarak çubuk analojisi metoduna göre yapılmıştır. Elde edilen tasarım sonuçları beton parametresi dışında tüm özellikleri aynı olan DA'lı yüksek kirişlerin tasarım sonuçları ile karşılaştırılmıştır. Yapılan karşılaştırmalardan aşağıdaki sonuçlar elde edilmiştir.

- Yüksek kirişlerde GDA oranı artıkça basınç çubuklarının kesit ve kapasite artış talebi artmaktadir.

- D bölgelerinin tasarımında mevcut yönetmeliklerin önermiş olduğu bağıntıların, GDA oranının \%25 ve altında olduğu yapısal elemanların tasarımında kullanılabileceği görülmüştür.

- Geri dönüşümlü agrega oranının \%50 ve üzerinde olduğu D bölgelerinin tasarımında mevcut yönetmelik bağıntılarının kullanılmasının yapısal tasarım açısından risk oluşturacağı belirlenmiștir.

- Mevcut bağıntıların \%50 ve üzeri GDA içeren betonların karakteristik özelliklerini temsil edecek şekilde revize edilmesi gerektiği sonucu elde edilmiştir.

Elde edilen sonuçlar mevcut çalışma çerçevesinde geçerlidir. Daha genel ve kapsayıcı sonuçlar elde etmek için daha kapsamlı deneysel ve analitik çalışmaların yapılmasına ihtiyaç duyulacaktır.

\section{Kaynaklar}

[1] European Commission Eurostat Statistics Database on Waste Statistics, Available online: https://appsso.eurostat.ec.europa.eu/nui/submitViewTableAction.do (accessed on 19 August 2021), (updated in 30.04.2021).

[2] United States Environmental Protection Agency (EPA), Sustainable Management of Construction and Demolition Materials. Available online:www.epa.gov/smm/sustainablemanagement-construction-and-demolition materials\#America (accessed on 19 August 2021). 
[3] Saribas I. Use of environmental friendly recycled aggregate concrete in production of structural members, PhD. Thesis, 2018. Graduate School of Science, Engineering and Technology, Istanbul Technical University.

[4] Goksu C, Saribas I, Binbir E, Akkaya Y, and Ilki A. Structural behavior of recycled aggregates concrete obtained from low quality concrete. Structural Engineering and Mechanics, 69(1), 2019, 77-93.

[5] Saribas I, Ok B. Seismic performance of recycled aggregate filled cantilever reinforced concrete retaining walls. (Special issue: Challenges for Structural Recycled Aggregate Concrete) Adv in Mech Eng 11(4), 2019, 1-11.

[6] Ilki A, Saribas I, Goksu C. Seismic behavior of reinforced recycled aggregate concrete members. Aca Pers Proc 2(2), 2019, 295-306.

[7] Saribas I. Performance assessment of reinforced recycled aggregate concrete plane frame structure. Aca Pers Proc 2(2), 2019a, 150-161.

[8] Saribas I, Goksu C, Binbir E, Ilki A. Seismic performance of full-scale RC columns containing high proportion recycled aggregate. Bull. Earthquake Eng. 17(11), 2019, 6009-6037.

[9] Saribas I, Goksu C, Binbir E, Ilki A. Shear-flexure interaction in RAC columns under simulated seismic actions. Eng Struc 231, 2021, 111746.

[10] Demir U, Unal G, Goksu C, Saribas I, Ilki A. Post-fire seismic behavior of RC columns built with sustainable concrete. J of Earth Eng. 2021.

[11] Xiao J. Recycled aggregate concrete structures. 2018, https://doi.org/10.1007/978-3-66253987-3.

[12] Xie T. Gholampour A, Ozbakkaloglu T. Toward the development of sustainable concretes with recycled concrete aggregates: comprehensive review of studies on mechanical properties. J Mater Civ Eng 11(1), 2018, 10-23.

[13] Xiao JZ, Li JB, and Zhang C. Mechanical properties of recycled aggregate concrete under uniaxial loading. Cem. Concr. Res. 35(6), 2005, 1187-1194.

[14] Du T, Wang WH, Liu ZX, Lin HL, and Guo TP. The complete stress-strain curve of recycled aggregate concrete under uniaxial compression loading. J. Wuhan Univ. Technol. 25(5), 2010, 862-865.

[15] Belen GF, Fernando MA, Diego CL, and Sindy SP. Stress-strain relationship in axial compression for concrete using recycled saturated coarse aggregate. Constr. Build. Mater. 25(5) 2011, 2335-2342.

[16] Peng, JL, Du T, Zhao TS, Song X, Tang JJ. Stress-Strain relationship model of recycled concrete based on strength and replacement rate of recycled coarse aggregate. J. Mater. Civ. Eng., 31(9) 2019, 04019189.

[17] Saribas I. Stress-strain model for recycled aggregate concretes, El-Cezerî J of Sci and Eng 6(1), 2019b, 156-165.

[18] Ritter W. Die Bauweise Hennebique (The Hennebique System). Schweizerische Bau-zeitung, Bd. XXXIII, 7, Zürich, 1899. 
[19] Mörsch E. Der Eisenbetonbau, seine theorie und anwendung (reinforced concrete, theory and application), Stuttgart, 1902.

[20] Mörsch E. Concrete-steel construction, Goodrich EP, McGraw-Hill, New York, 1909.

[21] ACI 318-19: Building Code Requirements for Structural Concrete and Commentary, ACI Committee 318, 2019.

[22] CSA A23.3-04: Design of Concrete Structures, Canadian Standards Association, Rexdale, Ontario, 2005.

[23] CSA-S6-06: Canadian Highway Bridge Design Code, Canadian Standards Assocition, Mississauga, Ontario 2006.

[24] DIN 1045-1: Building and Civil Engineering Standards Committee, Plain, Reinforced and Prestressed Concrete Structures, Part 1: Design and Construction Deutsches Institut für Normung (DIN-Normen), Berlin, Germany, 2001.

[25] NZS 3101-1: Concrete Design Committee or the Standards Council, Concrete Structures Standard: Part 1-The Design of Concrete Structures. Standards New Zealand, Wellington, 2001.

[26] AASHTO LRFD: Bridge Design Specifications, Third Edition, American Association of State Highway and Transportation Officials, Washington, DC 2007.

[27] CEB-FIP Model Code: Comité Euro-International du Béton, Thomas Telford Services, Ltd., London 1990.

[28] FIB: Recommendations for practical design of structural concrete. Fédération Internationale de la Précontrainte, London, 1999.

[29] Hognestad E. A study of combined bending and axial load in reinforced concrete members, University of Illinois Bulletin 49 no. 22, 1951.

[30] Turkiye Bina Deprem Yönetmeliği (TBDY 2018): Deprem Etkisi Altındaki Binaların Tasarımı için Esaslar, Ankara, Turkiye, 2018. 
[31] Martin BT, Sanders DH. Verification and implementation of strut-and-tie model in LRFD bridge design specifications. American Association of State Highway and Transportation Officials, 2007.

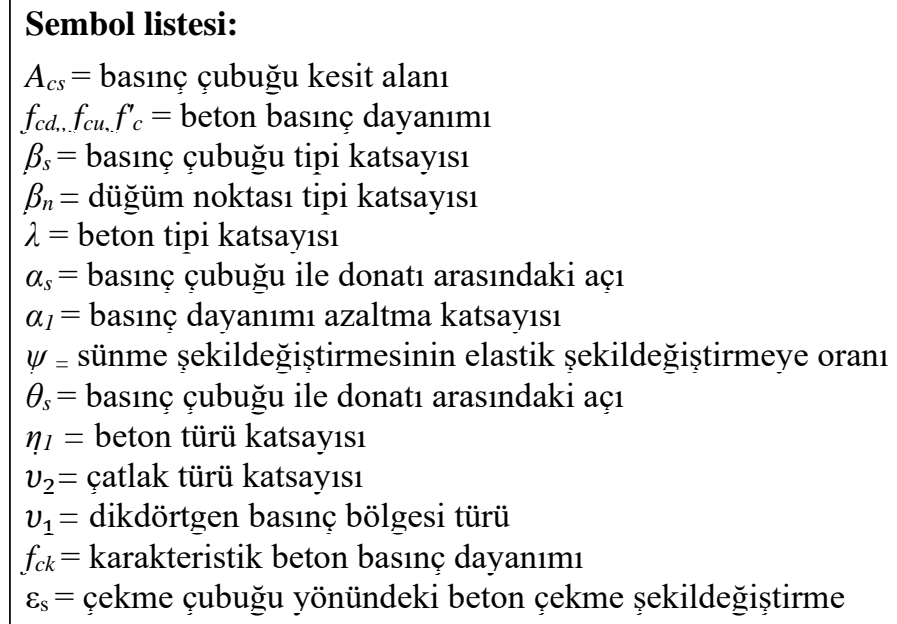

